\title{
Study on Dynamic Resilient Modulus Prediction of Subgrade Soil and Its Relevant Finite Element Method Implementation
}

\author{
DONG Cheng ${ }^{1, a}$, LIU Wen-jie ${ }^{1, b}$, ZHOU Lun ${ }^{1, c}$, ZHANG Rui-lei ${ }^{1, d}$ LI Zhi-yong ${ }^{1, e}$ \\ ${ }^{1}$ Hunan Communications Research Institute limited company, Changsha 410015, China \\ adongcheng4321@126.com, 'liuwjie@163.com, ${ }^{\mathrm{c}} 18769788330 @ 163 . c o m,{ }^{\mathrm{d}} 1454370514 @ q q . c o m$, \\ e389838205@qq.com
}

Key words : dynamic resilient modulus ; soil-water characteristic curve ; triaxial test; consistent tangent stiffness matrix; finite element method

Abstract : In order to investigate the effect of moisture content on cohesive subgrade soils dynamic resilient modulus, a series of dynamic-triaxial test were carried out. Based on the matric suctions measured by the filter paper method, the relationship between dynamic resilient modulus and matric suctions were analyzed. The study demonstrated that the dynamic resilient modulus values decrease with the increase of circular deviator stress and moisture content, in reverse of matric suctions. Considering that the dynamic resilient modulus is a function of deviator stress and bulk stress, based on the present three parameters compound constitutive model which reflects the effect of bulk stress and deviator stress, the effect of matric suctions which could indirectly reflect the effect of moisture content was introduced. And then the prediction model incorporating the effect of stress and moisture for cohesive subgrade soils was established. The model was utilized for experimental data regression analysis, a high coefficient of determination shows that the model is accurate and credible. Based on available model, an improved resilient modulus prediction model considering four parameters was proposed by introducing matric suction. Corresponding accurate consistent tangent stiffness matrix was derived. Afterward, the improved model was implemented into finite element method software and verification work was put forward.The prediction models not only can evaluate the long-term performance of subgrade soil in Southern China's rainy areas, but also can provide parameters for the pavement design based on dynamic method.

\section{Introduction}

The stability of long-term performance of subgrade has important influence on service performance of road. Currently, the static resilient modulus is a main indicator in pavement design, and it is taken as the design parameter in the middle wet state [1], but which does not consider the long-term effects of subgrade soil under traffic loads and environment. As one of main parameters that represent the mechanical properties of subgrade soil on flexible pavement mechanics-experience design method[2], the dynamic resilient modulus can better reflect the performance of subgrade soil. The domestic and international studies have shown that the main influence factors on the dynamic resilient modulus are soil group type, humidity, degree of compaction and stress conditions[3, 4]. When the filler type and degree of compaction are determined, the dynamic resilient modulus is mainly affected by humidity and stress state. When the roadbed is filled, it is generally compacted near the optimum moisture content [5]. However, during the operational phase, due to the impact of rainfall and groundwater, the moisture content of subgrade soil will gradually increase from the optimum moisture content (OMC) to the balance moisture content. Studies show that the equilibrium moisture content is generally higher $20 \%$ 30\% than the plastic limit[6]. Thadkamalla 
and George[7] have investigated 59 points of the moisture conditions of cohesive subgrade soil on LTPP, the results show that the moisture content of cohesive subgrade soil is higher than the optimum moisture content, and mainly distributed in the $\mathrm{OMC}-\mathrm{OMC}+7 \%$ range. This indicates that the moisture content of subgrade soil will change in a certain period of time, that is to say, the subgrade soil is in the non-saturated state during the entire operations. In Southern China, the climate is very damp, the influence of humidity on the subgrade soil is particularly significant. The services performance of pavement will directly affected by the stability of subgrade soil, therefore, carrying out the long-term performance of the subgrade soil under dynamic loads and environment has a very important significance. Based on the theory of unsaturated soil, the change of soil moisture will lead to the change of matric suction. So, the variety of matric suction may indirectly reflect the moisture condition of subgrade soil, and the soil water characteristic curve is the bond contacting the humidity and suction. Therefore, using the theory of unsaturated soil, the dynamic resilient modulus of cohesive subgrade soil can be studied.

Based on the dynamic triaxial test of subgrade soil under different moisture contents, one can obtain the influence of moisture content on the dynamic resilient modulus. In order to investigate the influence of matric suction on the resilient modulus, one can measure the matric suction bu the filter paper method when the dynamic triaxial test is completed. Then, the prediction model of dynamic resilient modulus which can reflect the influence of stress and humidity may be established. Corresponding accurate consistent tangent stiffness matrix was derived. Afterward, the improved model was implemented into finite element method software and verification work was put forward.

\section{Material and test method}

\section{Basic physical properties of soil}

Based on the test methods of soils for highway engineering [8], the basic physical properties of high liquid limit soil are listed in table 1.

Table 1 Basic properties of test specimens

\begin{tabular}{cccccc}
\hline Soil type & $\begin{array}{c}\text { maximum dry density } \\
/\left(\mathrm{g} \cdot \mathrm{cm}^{-3}\right)\end{array}$ & $\begin{array}{c}\text { optimum moisture } \\
\text { content } / \%\end{array}$ & $\begin{array}{c}\text { liquid limit } \\
/ \%\end{array}$ & $\begin{array}{c}\text { plastic limit } \\
/ \%\end{array}$ & $<0.075 \mathrm{~mm}$ \\
\hline clay & 1.652 & 18.5 & 48.4 & 23.6 & 62 \\
\hline
\end{tabular}

\section{Resilient modulus test}

According to the compaction test results, the soil sample is prepared in accordance with the target degree of compaction by universal testing machine. The diameter of soil sample is $10 \mathrm{~cm}$ and the height is $20 \mathrm{~cm}$. The British GDSLAB dynamic triaxial testing system is used here, which can dynamically control the axial displacement, axial force and confining pressure. The test load is half-sine and its frequency is $1 \mathrm{~Hz}$. The upload time is $0.1 \mathrm{~s}$ and the intermittent time is $0.9 \mathrm{~s}$. The loading sequence in dynamic triaxial test refers to NCHRP1-28A [9]' and at the same time, taking into the subgrade stress state of typical pavement structure [10]; In resilient modulus test, the number of load cycles is 100 times. Recording the average rebound deformation of the last five cycles of all levels of repetitive loads, the dynamic rebound modulus can be calculated by the following equation

$$
M_{R}=\sigma_{d} / \varepsilon_{\text {axial }}
$$

Where, $M_{R}$ is the resilient modulus; $\sigma_{d}$ is the deviatoric stress, $\sigma_{d}=\sigma_{1}-\sigma_{3} ; \sigma_{1}$ is the vertical 
stress, $\sigma_{3}$ is the confining pressure; $\varepsilon_{\text {axial }}$ is the average value of axial resilient.

\section{Matric suction measured by the filter paper method}

When measuring the suction by the filter paper method, it has the advantages of economy, accuracy, easy to operate, and the large measurement range. The model of filter paper is Whatman No.42. The calibration equation can be expressed as

$$
\left\{\begin{array}{l}
\log \psi_{m}=5.126-0.0568 \omega_{f} \\
\log \psi_{m}=2.804-0.0187 \omega_{f}
\end{array}\right.
$$

Where, $\psi_{m}$ is the matric suction; $\omega_{j}$ is the moisture content of filter paper.

\section{Results and discussion}

In order to analyze the influence of different moisture content on the dynamic resilient modulus of cohesive subgrade soil, four kinds of moisture content $\omega$ (OMC-3\%, OMC, OMC $+3 \%, \mathrm{OMC}+5 \%$, where, OMC is the optimum moisture content) are tested, and there are three samples under each moisture content.

\section{Impact of moisture content and matric suction on the resilient modulus}

While investigating the influence of moisture content on the dynamic resilient modulus of cohesive subgrade soil, the degree of compaction of each sample is $96 \%$. The curves of dynamical resilient modulus with different moisture content are shown in figure 2 when the confining pressure is $30 \mathrm{kPa}$. One can see from figure 2 that the dynamic resilient modulus is greater affected by the moisture content and it will reduce with the increase of the moisture content. The influence of deviatoric stress on the resilient modulus is not sensitive when the moisture content is OMC-3\%. However, while the moisture contents are $\mathrm{OMC}, \mathrm{OMC}+3 \%$, and $\mathrm{OMC}+5 \%$, the dynamic resilient modulus will significantly reduce with the increase of deviatoric stress.

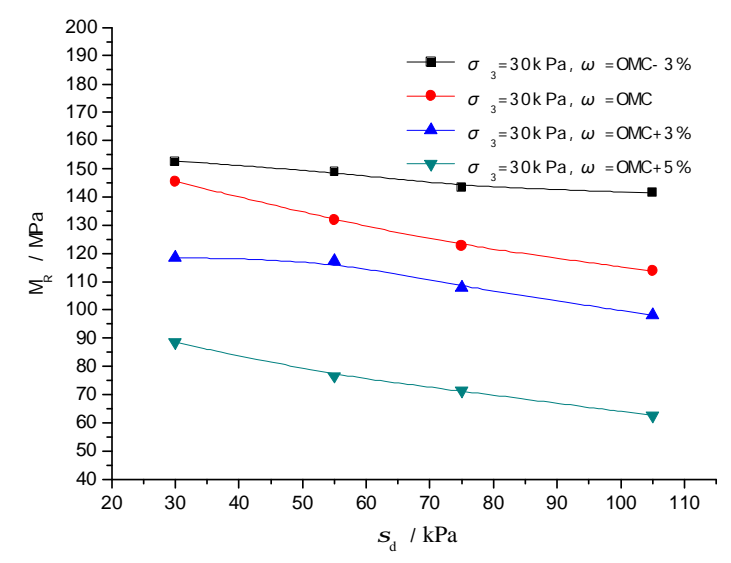

Fig.2Variation of dynamic resilient modulus under different moisture content

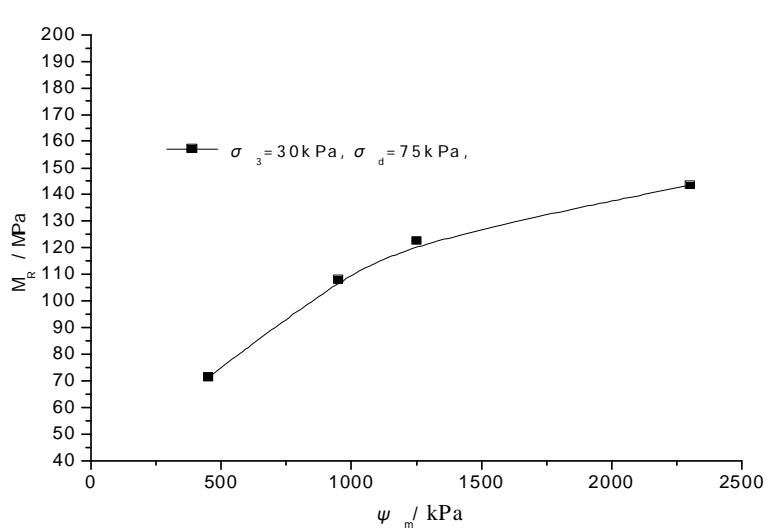

Fig.3 Variation of matric suction with dynamic resilient modulus

Because there is a specific function relationship between the matric suction and moisture content, the matrix suction can indirectly reflect the influence of humidity condition on the dynamic resilient modulus of subgrade soil, as shown in figure 3. One can see from figure 3 that the resilient modulus of clay may increase with the increase of the matric suction.

\section{Forecast model of the resilient modulus and analysis}

The test results show that the stress condition is the most important influence factor of resilient 
modulus. Therefore, when the prediction model of the dynamical resilient modulus is established, the relationship between stress and strain should be first established as accurately as possible, and the influence of other factors can be reflected by the model parameters. In the prediction model of the dynamical resilient modulus, there are three categories based on the stress variables [11, 12]. The composite model can fully reflect the mechanical traits of material. When the matric suction is added to the composite model, it can reflect the influence of the stress and humidity. The estimated equation(abbreviated as N37AP1) can be expressed as

$$
M_{\mathrm{R}}=k_{1} p_{\mathrm{a}}\left(\frac{\theta}{p_{\mathrm{a}}}\right)^{k_{2}}\left(\frac{\tau_{\text {oct }}+\chi \psi_{m}}{p_{\mathrm{a}}}\right)^{k_{3}}
$$

Where, $\theta=\sigma_{1}+\sigma_{2}+\sigma_{3}, \sigma_{1}, \sigma_{2}, \sigma_{3}$ are the main stresses; $\tau_{\text {oct }}=\sqrt{\left(\sigma_{1}-\sigma_{2}\right)^{2}+\left(\sigma_{1}-\sigma_{3}\right)^{2}+\left(\sigma_{2}-\sigma_{3}\right)^{2}} / 3$; $\psi_{m}$ is the matric suction; $\chi$ is the Bishop parameter of degree of saturation, when the soil is perfectly dry, $\chi=0$, when the soil is completely saturated, $\chi=1 . k_{i}$ is the regression constant; $P_{a}$ is the reference air pressure $(100 \mathrm{kPa})$. Loret and Khalili [13] deem that when $\psi_{m}<\psi_{e}$, the soil can be regarded as saturated, and can satisfy Terzaghi's principle of effective stress, so $\chi=1$. For the unsaturated soil, the test results show that there is a good correlation between $\chi$ and $\psi_{e} / \psi_{m}$, and it can be expressed as

$$
\chi=\left(\psi_{e} / \psi_{m}\right)^{0.55}
$$

The regression analysis results of model parameter are shown in table 2, and one can see from table 2 that there is a high coefficient of determination $\left(R^{2}>0.904\right)$ between the prediction model selected here and the experimental results. That is to say, the selected model has a higher rationality and reliability. $k_{2}$ reflects the impact of confining pressure; $k_{3}$ reflects the influence of the matric suction and deviator stress on the resilient modulus.

Table 2 Fitting parameters of dynamic resilient modulus prediction model

\begin{tabular}{ccccc}
\hline Soil type & $k_{1}$ & $k_{2}$ & $k_{3}$ & $R^{2}$ \\
\hline clay & 516.563 & -0.728 & 1.057 & 90.4 \\
\hline
\end{tabular}

\section{Derivation of consistent tangent matrix of N37AP1model}

An important purpose of establishing a prediction model in this article is to implement N37AP1 model to FEM calculation based on ABAQUS, which can be realized by utilizing UMAT (user materials subroutine) interface. Because each analysis step of nonlinear solution in ABAQUS is proceeded by generating consistent tangent stiffness matrix, derivation of N37AP1 model's consistent tangent stiffness matrix in form of stresses becomes a significant precondition. The solution procedure is as follows. The linear elastic constitutive relation can be expressed as :

$$
\boldsymbol{S}=E(\alpha \varepsilon \boldsymbol{I}+\boldsymbol{E}) /(1+v)
$$

where $\boldsymbol{E}$ is strain tensor; $\boldsymbol{S}$ is stress tensor; $E$ is modulus of linear elasticity; $\boldsymbol{\varepsilon}=\boldsymbol{t r}(\boldsymbol{E})$ is bulk strain; $\boldsymbol{v}$ is Poisson's ratio; $\boldsymbol{\alpha}$ is defined as: $\alpha=v /(1-2 v)$. Similar to linear elastic constitution, by replacing $E$ with stiffness matrix $\boldsymbol{M}_{\mathrm{r}}$, the nonlinear elastic constitutive relation is derived as:

$$
S=M_{r}(\alpha \varepsilon I+E) /(1+v)
$$


where $\boldsymbol{I}$ is unit matrix. Defining $C\left(\theta, \tau_{\text {oct }}\right)$ as:

$$
C\left(\theta, \tau_{o c t}\right)=\frac{M_{r}\left(\theta, \tau_{o c t}\right)}{1+v}=k P_{a}\left(\frac{\theta}{P_{a}}\right)^{k_{1}}\left(\frac{\tau_{o c t}+\chi \Psi_{m}}{P_{a}}\right)^{k_{2}}=k P_{a}\left(\frac{\theta}{P_{a}}\right)^{k_{1}}\left(\frac{\tau_{o c t}}{P_{a}}+A\right)^{k_{2}}
$$

where $k_{1}, k_{2}$ are parameters; $\theta$ is bulk stress (compression condition); $P_{a}$ is standard atmospheric pressure; $\tau_{\text {oct }}$ is octahedral shear stress; $k$ is defined as: $k=k_{1} /(1+v), A=\chi \psi_{m} / p_{a}$.

The consistent tangent stiffness matrix can be expressed as a function of deviator stress:

$$
\begin{aligned}
\frac{\partial \mathbf{S}}{\partial \mathbf{E}} & =C(\mathbf{1}+\alpha \mathbf{I} \otimes \mathbf{I})+\left(\frac{1}{3} \overline{\alpha \varepsilon} \mathbf{I}+\overline{\mathbf{E}}\right) \otimes \nabla_{\mathbf{E}} C \\
& =C(\mathbf{1}+\alpha \mathbf{I} \otimes \mathbf{I}+m \mathbf{L}) \\
& \mathbf{L}=\frac{\bar{\alpha} k_{2}\left(\tau_{o c t}+A P_{a}\right)}{3} \mathbf{I} \otimes \mathbf{I}+\frac{\bar{\alpha} k_{2}\left(\tau_{o c t}+A P_{a}\right)}{\sigma} \overline{\mathbf{S}} \otimes \mathbf{I}
\end{aligned}
$$

where

$$
+\frac{\sigma k_{3}}{9 \tau} \mathbf{I} \otimes \overline{\mathbf{S}}+\frac{k_{3}}{3 \tau} \overline{\mathbf{S}} \otimes \overline{\mathbf{S}}
$$

$$
\begin{aligned}
\nabla_{\mathbf{E}} \mathrm{C} & =m\left[\begin{array}{l}
\frac{\bar{\alpha} k_{2} \mathrm{C}^{2}}{\theta}\left(-k_{3} \tau_{o c t}+\tau_{o c t}+A P_{a}\right) \operatorname{sgn}(\varepsilon) \mathbf{I} \\
+\frac{\bar{\alpha} k_{2} k_{3} \tau_{o c t} C^{2}}{\theta} \operatorname{sgn}(\varepsilon) \mathbf{I} \\
+\frac{k_{2} k_{3} \mathrm{C}^{2}}{3} \frac{\overline{\mathbf{E}}}{\gamma}+\frac{k_{3} C^{2}\left(1-k_{2}\right)}{3} \frac{\overline{\mathbf{E}}}{\gamma}
\end{array}\right] \\
& =m\left(\frac{\bar{\alpha} k_{2} \mathrm{C}^{2}}{\sigma}\left(\tau_{o c t}+A P_{a}\right) \mathbf{I}+\frac{k_{3} C^{2}}{3} \frac{\overline{\mathbf{E}}}{\gamma}\right)
\end{aligned}
$$

It can be found from Eq.(8) that consistent tangent stiffness matrix is finally exhibited in terms of $\theta$ and $\tau_{\text {oct }}$, which are independent variable and can be calculated by stress tensor in analysis step. Afterward, stress increment can be calculated from strain increment and consistent tangent stiffness matrix. Stress tensor will be renewed and imported to the next analysis step. N37AP1 model will be recognized as material property in that progressive form until all the steps are finished. These procedures above were programed by Fortran language and compiled into ABAQUS through UMAT interface

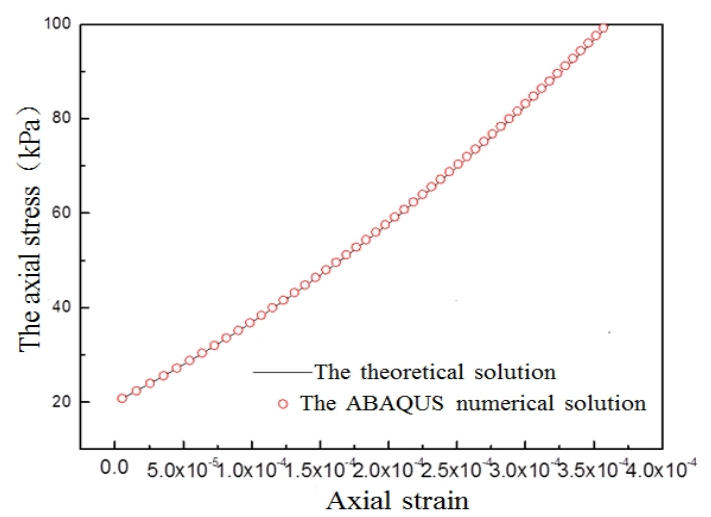

Fig.4 The axial stress-strain curve of the N37AP1 model

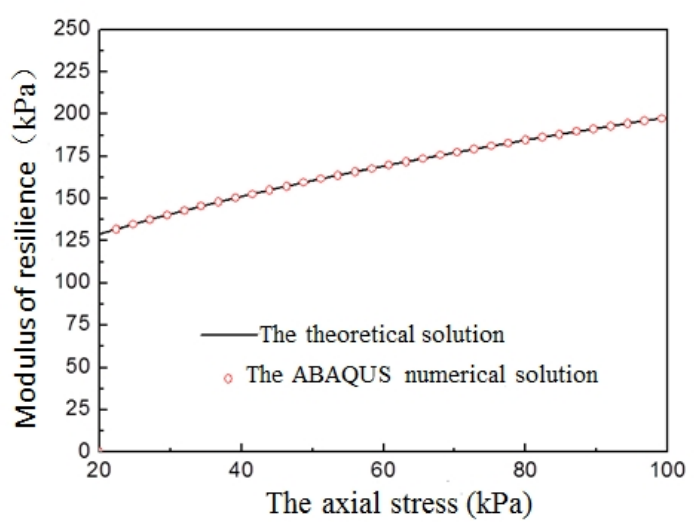

Fig.5The N37AP1 resilient modulus varies over time

The theoretical solution of the model was obtained by writing the program, the curve of stress strain and resilient modulus was obtained from figure 4 and figure 5. As can be seen from the diagram, the stress-strain curve and the resilient modulus of the model are fully consistent with the results obtained by ABAQUS, and the correctness of the numerical realization is verified. 


\section{Conclusions}

(1) The dynamic resilient modulus of cohesive subgrade soil will reduce with the increase of the cyclic deviator stress and moisture content, and will increase with the increase of the matric suction.

(2) Based on the three-parameter composite model, in which the partial stress and body stress are variables, the matric suction is introduced, and then the model of dynamic resilient modulus is established, that can consider the influence of humidity and stress state. It not only provides a basis for long-term performance of subgrade soil under environment and traffic loads, also provides the parameters for the pavement structure design based on the dynamic method.

(3) The regression analysis results indicate that the model used in this paper has a high coefficient of determination. It proved that the model considering the effects of stress and humidity is reasonable and reliable.

(4) The result shows that the stress-strain curves are very close to analytic solution, which indicates that derivation of Jacobian matrix and programming work are mainly correct.

\section{Acknowledgements}

This work was supported by the Youth Talents Support Program of Hunan (grant number 2016RS3037); Fund of Post-doctoral Studies. The authors would like to thank all the members of Key Laboratory at Hunan Communication Research Institute, Changsha, China.

\section{References}

[1] JTG D50-2006.Specifications for Design of Highway Asphalt Pavement[S].

[2] HUANG Yang-xian. Pavement analysis and design [M]. Beijing: China Communications Press, 1998: 215-220.

[3] UZAN J. Characterization of granular material[C]. Proceedings Transportation Research Record 1022. Washington:1985:52-59.

[4] LING Jian-ming,SU Hua-cai,XIE Hua-chang, et al.Library research on dynamic resilient modulus of subgrade soil[J]. Chinese Journal of Underground Space and Engineering, 2010,6(5): 919-925.

[5] JTG D30-2004. Specifications for Design of Highway Subgrades [S].

[6] UZAN J. Characterization of clayey subgrade materials for mechanistic design of flexible pavement[C]. In Transportation Research Record: Journal of the Transportation Research Board, No.1629,TRB,National Research Council.Washington,1998,188-196.

[7] Thadkamalla G.B, George KP. Characterization of subgrade soils at simulated field moisture[C]. In Transportation Research Record: Journal of the Transportation Research Board, No. 1481, 21-27, 1995.

[8] JTG E40-2007.Test Methods of Soils for Highway Engineering[S].

[9] NCHRP Laboratory determination of resilient modulus for flexible pavement design, project 1-28[R]. Washington DC. National Cooperative Highway Research Program,1997.

[10] CHEN Sheng-kai, LING Jian-ming, ZHANG Shi-zhou. Fixing loading sequence for resilient modulus test of subgrade soil [J]. Highway, 2006, (11):148-152.

[11] LING Jian-ming, CHEN Sheng-kai, CAO Chang-wei. Analysis of influence factors on resilient modulus of subgrade soils [J]. Journal of Building Materials, 2007, 10(4):446-451.

[12] LEKARP F,ISACSSON U,DAWSON A. State of the Art I: Resilient response of unbound aggregates. Journal of Transportation Engineering [J]. 2000, 126(1):66-75.

[13] Loret B, Khalili N. An effective stress elastic-plasticmodel for unsaturated porous media[J].Mechanics of Materials, 2002,34:97-116. 